\title{
Community physicians' knowledge of secondary prevention after ischemic stroke: a questionnaire survey in Shanxi Province, China
}

\author{
Chen Chen ${ }^{1}$, Xiaoyuan Qiao ${ }^{2}$, Huijie Kang ${ }^{1}$, Ling Ding ${ }^{1}$, Lixia Bai ${ }^{1}$ and Jintao Wang ${ }^{1 *}$
}

\begin{abstract}
Background: This cross-sectional, questionnaire-based survey, conducted in Shanxi Province, China, evaluated the knowledge of community physicians of secondary prevention of ischemic stroke and transient ischemic attacks (TIAs).

Methods: A total of 1910 physicians practicing at 832 community-based clinics, hospitals and other care centers in 11 prefectures of Shanxi Province completed the questionnaires between 1 July and 30 September 2013.

Results: Over $90 \%$ of participants were aware of the most common risk factors for stroke, but lifestyle-related factors were seen as of low or medium importance for secondary prevention. Only about $50 \%$ of physicians were aware of the existence of commonly used stroke scales, and fewer said that they would use those scales in their clinical practice. There were slight differences in the responses to some of the questions on risk factors and stroke scales were associated with the physicians' gender, academic qualifications, practice duration and location. Less than half of the participants were aware of the secondary prevention recommendations included in the most recent guidelines.

Conclusion: The survey revealed a huge gap in knowledge of current guidelines for secondary prevention of ischemic stroke and TIA among the physicians surveyed. Continuing education and training of community physicians, administered as a public health program, is needed to improve the healthcare of ischemic stroke and TIA patients.
\end{abstract}

Keywords: Ischemic stroke, Transient ischemic attack, Secondary prevention, Community physician

\section{Background}

The mortality of ischemic and hemorrhagic stroke is decreasing worldwide, resulting in an increase in the number of stroke survivors, especially in low- and middle-income countries [1]. Patients who have had an ischemic stroke or transient ischemic attack (TIA) have a high risk of recurrence; and in Western countries, approximately $8-12 \%$ of patients experience a second event within the first year after a stroke or TIA [2, 3]. The National Stroke Registry of China reported that $17.7 \%$ of 11,560 patients with ischemic stroke or TIA, experienced a recurrence within 1 year [4]. This geographical difference may be partly explained by the relatively high prevalence of intracranial

\footnotetext{
*Correspondence: wjtsx03@163.com

'Department of Epidemiology, School of Public Health, Shanxi Medical University, Taiyuan, Shanxi Province, China

Full list of author information is available at the end of the article
}

large-artery disease in the Chinese compared with Western populations and the particularly high risk of recurrent ischemic stroke with that etiology. On the other hand, it might also be attributed to gaps in the professional education of practicing physicians and their familiarity with current guidelines for secondary prevention in China [5]. Such gaps would hinder timely and accurate risk evaluation, stratification, and optimal medical management, as well as the best use of antiplatelet, anticoagulant, or interventional/surgical therapies, which are all important for secondary prevention. Improved knowledge and awareness would be expected to result in a reduced risk of recurrence in stroke patients $[6,7]$.

A large, nationwide survey of secondary stroke prevention, conducted in 3489 Chinese general physicians and neurologists, reported a lack of adequate awareness of 


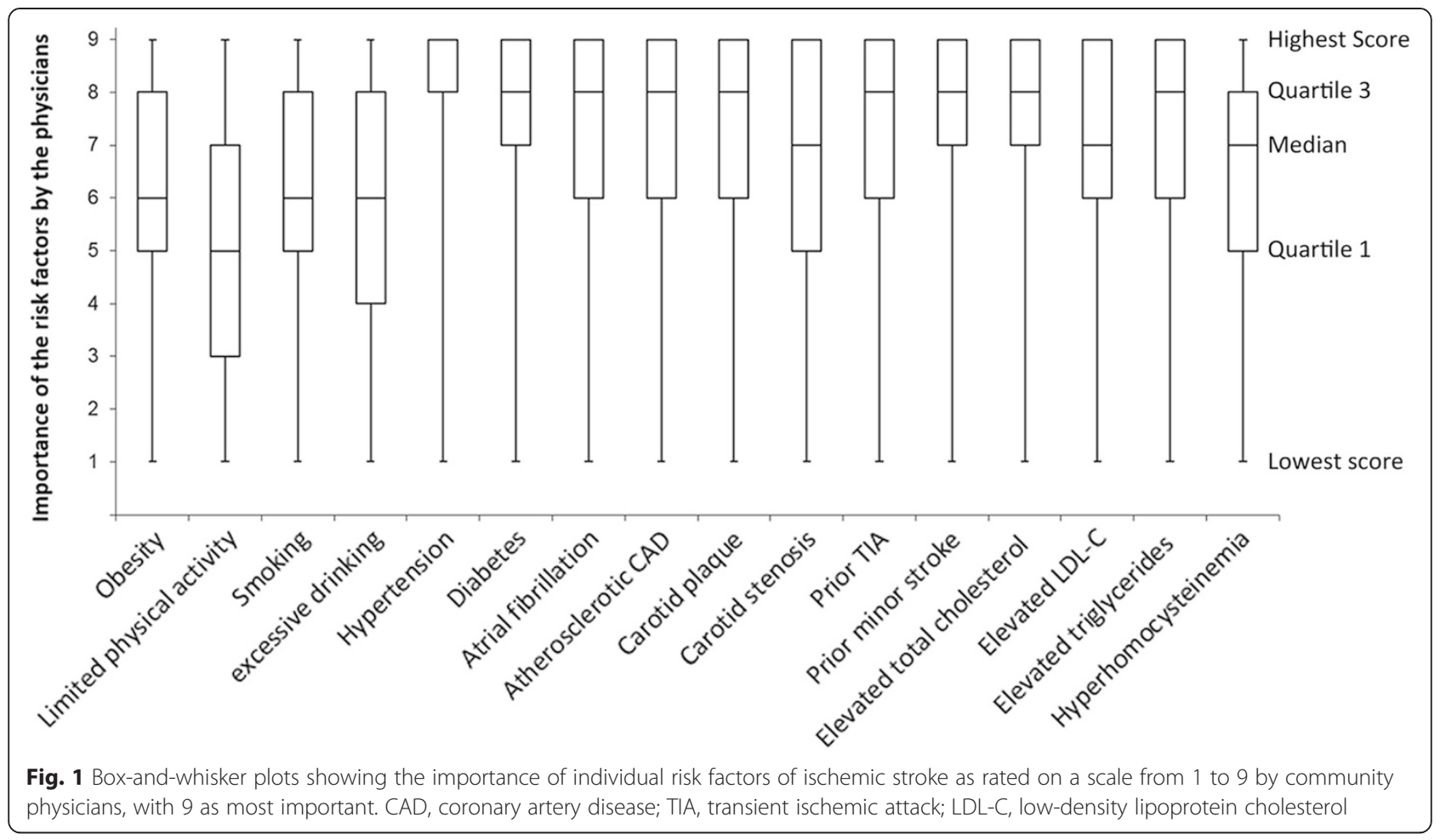

the Chinese National Guidelines for Prevention of Ischemic Stroke and Transient Ischemic Attack [8] The survey participants were either general practitioners or specialists [5], but their responses did not accurately represent the level of professional knowledge that many practicing Chinese community physicians have. For example, in Shanxi Province, located in the center of the Yellow River Valley of northern China, all community physicians are involved in the care of stroke patients. However, little is known of their knowledge of the aspects of stroke relevant to recurrence, and no standardized training or continuing education programs in the area of stroke are currently available to them. This survey of the community physicians in Shanxi Province, where our medical university is located, was conducted to identify existing gaps in the professional knowledge of stroke. The results may assist in the implementation of appropriate continuing education programs intended to reduce the risk of recurrent stroke.

\section{Methods}

\section{Ethics statement}

This cross-sectional study surveyed currently licensed physicians practicing in community-based clinics, hospitals and other care centers in Shanxi Province, China, and was approved by the Ethics Committee of Shanxi Medical University. A questionnaire with selected response questions was mailed to all physicians practicing in clinics in the 11 prefectures of Shanxi Province, and all of those who responded provided written, informed consent before completing the survey.

\section{Questionnaire survey}

The Shanxi Provincial Health Bureau sent the questionnaires to the local health authorities of 11 prefectures in the province, which then forwarded them to all the general physicians in their communities. A pilot survey of 10 physicians in two communities was conducted before initiation of the study to estimate the response and questionnaire completion rates of potential participants.

The participants were asked to provide personal information including their age, gender, and demographic information, including the number of years in practice and their academic qualifications. Questions on knowledge of secondary prevention of ischemic stroke and TIA were developed to reflect the most recent Chinese stroke rehabilitation management [9] and American Heart Association/American Stroke Association (AHA/ASA) guidelines $[7,10]$. The questionnaire covered three major areas. The first part consisted of multiple-choice questions about common risk factors of ischemic stroke is shown in Fig. 1, including obesity, limited physical activity, smoking, excessive drinking, histories of hypertension, diabetes, atrial fibrillation, atherosclerotic coronary/carotid artery diseases, prior TIA/minor stroke, dyslipidemia (elevated total cholesterol, low-density lipoprotein cholesterol, or triglycerides) and hyperhomocysteinemia [7, 10]. The participants were asked for their awareness of these risk factors, and to rate 
each risk factor on a scale of 1 to 9 , with 9 indicating the highest importance. The second part consisted of "yes or no" questions related to the awareness of commonly used clinical scores to evaluate the severity or prognosis of ischemic stroke or TIA. The questions were based on the National Institutes of Health Stroke Scale (NIHSS) [11] and its Chinese version (C-NIHSS) [12], and the Scandinavian Stroke Scale (SSS) [13], as well as the $\mathrm{ABCD}$ score (A, age; $\mathrm{B}$, blood pressure; $\mathrm{C}$, clinical features; and $\mathrm{D}$, duration of symptoms) for TIA [14]. The physicians were also asked if they would use those scores to evaluate any suspected ischemic stroke or TIA cases. The third part examined knowledge of acute treatment and secondary prevention of ischemic stroke, and consisted of multiplechoice questions on aspects such as thrombolytic, antiplatelet, anticoagulant, and antihypertensive therapies.

\section{Statistical analysis}

Descriptive statistics were used to summarize the study results. Age and number of years in practice were expressed as means \pm SD. Ordinal variables (e.g., scoring of the importance of risk factors) were expressed as medians with interquartile (IQR) ranges and box-andwhisker plots. Categorical demographic variables and responses to the multiple-choice and "yes or no" items in the questionnaire were given as numbers (percentages). The number of community physicians who completed and returned the questionnaire was considered as the denominator for all proportion calculations. Bar charts were used to reveal the community physicians' awareness of common risk factors and scoring systems for ischemic stroke or TIA. Chi-square tests were performed to determine the significance of differences in the awareness of risk factors and stroke scales in male and female physicians and in physicians with different academic qualifications, practice durations, and practice locations. All statistical analyses were carried out by SPSS version 13.0 (SSPS Inc, Chicago, USA). Two-sided $P$-values $<0.05$ were considered statistically significant.

\section{Results}

\section{Participant demographics}

A total of 1,918 questionnaires were mailed to physicians at 832 community-based clinics, hospitals and other care centers in 11 prefectures of Shanxi Province, China, from 1 July to 30 September 2013. Of these, 1,910 were completed and returned, for a response rate of over $99 \%$. Of the participating physicians, 780 (40.8\%) were men, and 1130 (59.2\%) were women. Their mean age was $43 \pm 14$ years, and they had practiced for a mean of $15 \pm 15$ years. The highest academic qualification in this group of community physicians was a 3-year junior college degree in medicine, earned by 1346 participants (70.5 \%), 455 (23.8 \%) had a 4-year bachelor's degree, and $15(0.8 \%)$ had an additional 2 to 3-year master's degree. Ninety-four participants $(4.9 \%)$ were traditional Chinese medicine practitioners who had been trained by their predecessors and did not have a formal tertiary qualification.

\section{Knowledge of common risk factors of ischemic stroke}

Awareness of common risk factors for ischemic stroke, as measured by the questionnaire, is shown in Table 1 . More than $90 \%$ the surveyed physicians were aware of the risk factors. However, nearly $30 \%$ did not consider limited physical activity as a stroke risk; and obesity, smoking, and excessive alcohol consumption were under appreciated, as indicated by median scores of 5 or 6 on a scale in which 9 indicated the highest importance.

Differences in the perceived importance of individual stroke-risk factors that were reported by male and female physicians and by physicians with different academic qualifications, duration and location of practice are also shown in Table 1. There was no significant difference between male and female physicians in awareness of the surveyed risk factors, except for atherosclerotic coronary artery disease, which female physicians scored as being more important than male physicians did $(P=0.013)$. Physicians with shorter practice durations were more aware of the importance of limited physical activity and hyperhomocysteinemia as risk factors than were physicians in practice for longer periods of time. The degree of awareness of a number of risk factors were significantly different in community physicians with different academic qualifications or practice location, but the absolute differences in percentage were small and may not be meaningful in practice.

\section{Knowledge of commonly used stroke scales}

Awareness of commonly used stroke and TIA evaluation scores and their willingness to use them in their practices are shown in Table 2. Only $39.8 \%, 55.0 \%$ and $20.0 \%$ of the community physicians, respectively, were aware of using the NIHSS, C-NIHSS, and SSS scores to evaluate the neurological deficits of stroke or TIA patients, and only $45.4 \%$ of the physicians indicated they would use NIHSS or C-NIHSS criteria to evaluate potential stroke patients in their clinical practice. Only $46.9 \%$ of the physicians were aware of the ABCD score, and only $18.9 \%$ of them would use it to evaluate potential TIA patients in their clinical practice.

There was no significant difference between male and female physicians in their awareness of or willingness to use these scales (Table 2). The awareness of SSS and C-NIHSS differed among physicians with different practice duration and location as well as in those with the highest academic qualification and traditional Chinese medicine practitioners. There was a trend toward increased 
Table 1 Gender, academic qualifications, practice duration and location and awareness of common risk factors for ischemic stroke

\begin{tabular}{|c|c|c|c|c|c|c|c|c|c|c|c|c|c|c|c|c|}
\hline & \multirow{3}{*}{$\frac{\text { Total }}{N=1910}$} & \multicolumn{3}{|l|}{ Gender } & \multicolumn{4}{|c|}{ Highest academic qualification } & \multirow{3}{*}{ P value } & \multicolumn{4}{|c|}{ Practice duration } & \multicolumn{3}{|c|}{ Location of practicing } \\
\hline & & Male & Female & P value ${ }^{*}$ & $\begin{array}{l}\text { Junior } \\
\text { college } \\
\text { degree }\end{array}$ & $\begin{array}{l}\text { Bachelor's } \\
\text { degree }\end{array}$ & $\begin{array}{l}\text { Master's } \\
\text { degree }\end{array}$ & $\begin{array}{l}\text { TCM } \\
\text { practitioners } \\
\text { with no }\end{array}$ & & $<10$ years & $\begin{array}{l}10-20 \\
\text { years }\end{array}$ & $>20$ years & P value ${ }^{*}$ & Rural & Urban & P value $e^{*}$ \\
\hline & & $(n=780)$ & $(n=1,130)$ & & $(n=1,346)$ & $(n=455)$ & $(n=15)$ & $\begin{array}{l}\text { college } \\
\text { education } \\
(n=94)\end{array}$ & & $(n=650)$ & $(n=917)$ & $(n=343)$ & & $(n=454)$ & $(n=1,456)$ & \\
\hline Obesity & 96.7 & 96.6 & 96.9 & 0.807 & 96.5 & 96.8 & 100 & 100 & 0.321 & 96.5 & 96.4 & 97.4 & 0.614 & 98.0 & 96.4 & 0.154 \\
\hline $\begin{array}{l}\text { Limited physical } \\
\text { activity }\end{array}$ & 73.2 & 73.3 & 73.0 & 0.884 & 74.1 & 67.6 & 66.7 & 76.8 & 0.070 & 76.3 & 73.2 & 68.4 & 0.037 & 74.9 & 72.7 & 0.431 \\
\hline Smoking & 96.3 & 96.6 & 96.0 & 0.475 & 96.1 & 95.5 & 100 & 98.8 & 0.457 & 96.9 & 95.8 & 96.7 & 0.561 & 97.4 & 96.0 & 0.219 \\
\hline Excessive drinking & 94.3 & 93.2 & 95.0 & 0.123 & 93.5 & 95.8 & 93.3 & 98.8 & 0.108 & 95.5 & 94.7 & 92.0 & 0.069 & 93.0 & 94.6 & 0.239 \\
\hline Hypertension & 99.7 & 99.6 & 99.8 & 0.402 & 99.7 & 99.8 & 100 & 100 & 0.969 & 99.8 & 99.5 & 99.8 & 0.738 & 99.7 & 99.7 & 0.982 \\
\hline Diabetes & 96.1 & 96.7 & 95.7 & 0.321 & 95.6 & 97.3 & 86.7 & 96.4 & 0.137 & 95.8 & 96.4 & 95.3 & 0.669 & 92.5 & 97.0 & $<0.001$ \\
\hline Atrial fibrillation & 92.0 & 90.8 & 92.7 & 0.152 & 91.5 & 93.5 & 93.3 & 87.7 & 0.308 & 89.5 & 91.9 & 92.4 & 0.278 & 89.1 & 92.7 & 0.028 \\
\hline Atherosclerotic CAD & 95.2 & 93.6 & 96.2 & 0.013 & 95.1 & 94.8 & 93.3 & 96.3 & 0.930 & 92.7 & 96.5 & 93.6 & 0.930 & 94.7 & 95.3 & 0.648 \\
\hline Carotid plaque & 96.7 & 95.9 & 97.2 & 0.146 & 95.9 & 98.2 & 100 & 100 & 0.032 & 95.2 & 96.4 & 97.6 & 0.170 & 96.5 & 96.7 & 0.841 \\
\hline Carotid stenosis & 94.9 & 94.3 & 95.2 & 0.408 & 93.9 & 96.7 & 93.3 & 97.5 & 0.115 & 92.6 & 95.7 & 94.5 & 0.090 & 92.6 & 95.4 & 0.037 \\
\hline Prior TIA & 98.0 & 97.2 & 98.5 & 0.056 & 97.5 & 99.5 & 93.3 & 96.4 & 0.041 & 98.1 & 97.9 & 97.2 & 0.616 & 98.2 & 97.9 & 0.720 \\
\hline Prior minor stroke & 98.0 & 97.7 & 98.1 & 0.545 & 97.9 & 98.0 & 93.3 & 97.5 & 0.665 & 97.6 & 97.6 & 98.1 & 0.848 & 99.4 & 97.6 & 0.038 \\
\hline $\begin{array}{l}\text { Elevated total } \\
\text { cholesterol }\end{array}$ & 98.3 & 97.9 & 98.5 & 0.462 & 97.5 & 99.8 & 100 & 100 & 0.015 & 97.9 & 98.1 & 98.6 & 0.715 & 99.1 & 98.0 & 0.163 \\
\hline Elevated LDL-C & 92.2 & 92.4 & 92.1 & 0.927 & 91.8 & 94.1 & 80.0 & 89.0 & 0.092 & 93.5 & 91.6 & 89.5 & 0.121 & 91.8 & 92.3 & 0.761 \\
\hline $\begin{array}{l}\text { Elevated } \\
\text { triglycerides }\end{array}$ & 98.0 & 97.8 & 98.2 & 0.604 & 97.3 & 99.5 & 100 & 100 & 0.021 & 97.6 & 97.8 & 98.1 & 0.872 & 99.1 & 97.8 & 0.100 \\
\hline Hyperhomocysteinemia & 89.9 & 88.4 & 90.9 & 0.094 & 89.1 & 92.2 & 80.0 & 86.8 & 0.149 & 91.1 & 90.6 & 84.7 & 0.004 & 87.9 & 90.4 & 0.182 \\
\hline
\end{tabular}

TCM traditional Chinese medicine, CAD coronary artery disease, TIA transient ischemic attack, $L D L-C$ low-density lipoprotein cholesterol

"Chi-square test, $P<0.05$ indicates a significant difference in awareness between groups.

aValues are given as percentages 
Table 2 Gender, academic qualification, practice duration, and location and awareness of and willingness to use commonly used stroke-scoring scales ${ }^{a}$

\begin{tabular}{|c|c|c|c|c|c|c|c|c|c|c|c|c|c|c|c|c|}
\hline & \multirow{3}{*}{$\frac{\text { Total }}{\mathrm{N}=1910}$} & \multicolumn{3}{|l|}{ Gender } & \multicolumn{4}{|c|}{ Highest academic qualification } & \multirow{3}{*}{ P value* } & \multicolumn{4}{|c|}{ Practice duration } & \multicolumn{3}{|c|}{$\underline{\text { Location of practicing }}$} \\
\hline & & Male & Female & P value* & $\begin{array}{l}\text { Junior } \\
\text { college } \\
\text { degree }\end{array}$ & $\begin{array}{l}\text { Bachelor's } \\
\text { degree }\end{array}$ & $\begin{array}{l}\text { Master's } \\
\text { degree }\end{array}$ & $\begin{array}{l}\text { TCM practitioners } \\
\text { with no college } \\
\text { education }\end{array}$ & & $<10$ years & $\begin{array}{l}10-20 \\
\text { years }\end{array}$ & $>20$ years & $P$ value ${ }^{*}$ & Rural & Urban & $P$ value* \\
\hline & & $(n=780)$ & $(n=1,130)$ & & $(n=1,346)$ & $(n=455)$ & $(n=15)$ & $(n=94)$ & & $(n=650)$ & $(n=917)$ & $(n=343)$ & & $(n=454)$ & $(n=1,456)$ & \\
\hline $\begin{array}{l}\text { Awareness of } \\
\text { NIHSS }\end{array}$ & 39.8 & 42.2 & 38.4 & 0.120 & 38.3 & 43.0 & 50.0 & 32.0 & 0.171 & 37.8 & 38.7 & 40.9 & 00.643 & 36.8 & 40.7 & 0.192 \\
\hline $\begin{array}{l}\text { Awareness of } \\
\text { C-NIHSS }\end{array}$ & 55.0 & 56.3 & 54.1 & 0.363 & 54.1 & 59.3 & 60.0 & 41.7 & 0.021 & 51.7 & 55.9 & 53.7 & 0.370 & 47.5 & 56.9 & 0.001 \\
\hline $\begin{array}{l}\text { Use of } \\
\text { NIHSS/C-NIHSS } \\
\text { in stroke cases }\end{array}$ & 45.4 & 46.0 & 45.0 & 0.721 & 46.3 & 41.7 & 50 & 41.1 & 0.390 & 41.8 & 45.7 & 50.0 & 0.113 & 50.0 & 44.3 & 0.098 \\
\hline $\begin{array}{l}\text { Awareness } \\
\text { of SSS }\end{array}$ & 20.0 & 21.4 & 19.2 & 0.244 & 18.0 & 24.5 & 13.3 & 19.0 & 0.033 & 18.9 & 16.1 & 22.1 & 0.041 & 21.6 & 19.6 & 0.404 \\
\hline $\begin{array}{l}\text { Awareness of } \\
A B C D \text { score }\end{array}$ & 46.9 & 46.3 & 47.4 & 0.640 & 45.1 & 51.4 & 33.3 & 39.2 & 0.052 & 47.5 & 45.8 & 45.2 & 0.770 & 43.0 & 48.0 & 0.085 \\
\hline $\begin{array}{l}\text { Use of } A B C D \\
\text { score in TIA } \\
\text { cases }\end{array}$ & 18.9 & 19.8 & 18.4 & 0.730 & 18.8 & 17.2 & 23.1 & 13.3 & $<0.001$ & 17.8 & 18.0 & 19.7 & 0.550 & 18.7 & 19.0 & 0.072 \\
\hline
\end{tabular}

TCM traditional Chinese medicine, NIHSS National Institutes of Health Stroke Scale, C-NIHSS Chinese version of NIHSS, SSS Scandinavian Stroke Scale, ABCD acronyms: A Age, B Blood pressure, C Clinical features, D Duration of symptoms, TIA transient ischemic attack

"Chi-square test

avalues are reported as percentages 
awareness of, and willingness to use, the NIHSS/C-NIHSS among those with bachelor's or master's degrees than among those without a tertiary qualification. Physicians with a junior college or a bachelor's degree had more knowledge of the ABCD score than those with a master's degree.

\section{Knowledge of secondary prevention strategies in ischemic stroke or TIA}

The responses to questions on acute treatment and secondary prevention of ischemic stroke or TIA are shown in Table 3. Only $14.4 \%$ of the community physicians were aware of the most recently recommended 4.5-h time window for intravenous thrombolytic therapy of acute ischemic stroke (Q1), while $35.9 \%$ chose the 3-h time window that was included in the previous international guidelines [15]. Only around $50 \%$ of the physicians were aware of the recommendations for antihypertensive therapy in ischemic stroke or TIA patients with elevated blood pressure $(\mathrm{Q} 2, \mathrm{Q} 3)$ contained in the most recent guideline [7]. A total of $65.3 \%$ of the physicians chose oral anticoagulants as the first-choice medication for cardioembolic ischemic stroke or TIA patients with atrial fibrillation (Q5), and $78.9 \%$ were aware of the target range of the international normalized ratio (INR, Q6). Only $26.4 \%$ were aware that the guidelines recommend the use of aspirin alone for patients who are unable to take oral anticoagulants (Q7) [7], and over half (52.8 \%) chose clopidogrel plus aspirin. A majority of physicians (67.0\%) would use antiplatelet medications to prevent recurrence of noncardioembolic ischemic stroke, TIA, or other cardiovascular events (Q10). Only $40.5 \%$ were aware that dual antiplatelet therapy with aspirin plus clopidogrel (Q11) is not currently recommended for routine secondary prevention after ischemic stroke or TIA [7]. In addition, only $11.4 \%$ were aware of the recommendation for reducing homocysteine level (Q12), and $46.8 \%$ were aware of the recommendation for postmenopausal hormone therapy (Q13) in ischemic stroke or TIA patients.

\section{Discussion}

We used a questionnaire to survey the knowledge of acute treatment and secondary prevention for ischemic stroke and TIA in a group of 1910 community physicians with an average of 15 years of practice in Shanxi Province, China. The responses revealed a huge gap among the participants in knowledge and clinical application of the most recent Chinese and AHA/ASA treatment guidelines for secondary prevention of ischemic stroke and TIA. The results demonstrate the need to implement a new policy for continuing medical education and training in advances in the care of stroke and TIA patients. Keeping up-to-date with new developments in patient care and secondary prevention would reduce the risk of stroke recurrence.

Most community physicians were aware of the common risk factors for ischemic stroke and TIA. However, despite the extensive evidence that lifestyle modifications have beneficial effects on multiple stroke risk factors, many of the physicians surveyed considered lifestylerelated risk factors to be less important than the other modifiable or nonmodifiable risk factors. Gender, academic level, practice duration, and practice location all affected physician awareness of some of the risk factors surveyed, but the differences were not significant. Knowledge of commonly used stroke scales was severely inadequate regardless of gender, academic qualifications, practice duration, or practice location. Approximately half the physicians were aware of NIHSS, C-NIHSS, SSS, and $A B C D$ scores, but fewer than half were willing to use those scores to evaluate stroke or TIA patients. In particular, timely use of the ABCD score in TIA patients could help to identify those at high risk of a subsequent stroke in the first few hours and days after TIA onset [14]. Standard procedures stipulate that such patients should be promptly transferred or referred to a tertiary hospital with a stroke care center. However, insufficient knowledge about use of the ABCD score may severely hinder timely risk stratification of TIA patients, especially for those whose symptoms have resolved and who seek help from community physicians without immediately going to the tertiary hospitals with stroke care centers. The community physicians participating in this study did not possess adequate knowledge of the secondary prevention measures recommended by the latest guidelines. Long-term adherence to these measures is crucial for preventing recurrent stroke and other cardiovascular events in those patients with post-ischemic stroke or TIA [7].

A study of over 2000 ischemic stroke or TIA patients discharged from 106 hospitals participating in the AHA's Get With The Guidelines stroke program in the United States between July 2006 and July 2008, found that $87.1 \%, 68.2 \%$, and $87.9 \%$, respectively, continued to adhere to antiplatelet, anticoagulant (warfarin), and antihypertensive medications at 1 year after discharge [16]. Since then, the Get With The Guidelines stroke program has significantly enhanced the quality of care of stroke patients in the United States, including secondary prevention [17]. Although similar programs have been established in China, (e.g., the China National Stroke Registry and the National Center for Stroke Care Quality Control) $[18,19]$, there are still huge evidence-based practice gaps in the secondary prevention of ischemic stroke and TIA. The long-term adherence to secondary prevention measures in Chinese stroke patients is lower than that reported in the American studies, especially in 
Table 3 Numbers and proportions of community physicians' $(N=1,910)$ answers to multiple-choice questions on acute treatment and secondary prevention of ischemic stroke or $\mathrm{TIA}^{\mathrm{a}}$

\begin{tabular}{|c|c|c|}
\hline Questions \& Answers & Numbers & Proporti \\
\hline \multicolumn{3}{|c|}{ Q1. For eligible ischemic stroke patients, what is the recommended time window for intravenous fibrinolytic therapy with rtPA? } \\
\hline 3 hours & 686 & $35.9 \%$ \\
\hline 4 hours & 180 & $9.4 \%$ \\
\hline 4.5 hours $^{\mathrm{b}}$ & 275 & $14.4 \%$ \\
\hline 6 hours & 769 & $40.3 \%$ \\
\hline
\end{tabular}

Q2. In secondary prevention for ischemic stroke or TIA, which of the following antihypertensive recommendations should be used in patients with elevated blood pressure?

\begin{tabular}{lr}
$20 / 15 \mathrm{mmHg}$ & 330 \\
$15 / 10 \mathrm{mmHg}$ & $600 \%$ \\
$10 / 5 \mathrm{mmHg}^{\mathrm{b}}$ & $31.4 \%$ \\
$5 / 0 \mathrm{mmHg}$ & $945 \%$ \\
\hline
\end{tabular}

Q3. If necessary to prevent recurrent stroke or other vascular events in ischemic stroke or TIA patients, when is it recommended to initiate antihypertensive therapy?

Immediately

Beyond 24 hours $^{b}$

Beyond 1 week

Beyond 2 weeks

Q4. What is the approximate percentage of cardiogenic cerebral embolism in all ischemic strokes?

$$
5 \%
$$

$10 \%$

Q5. For ischemic stroke or TIA patients with AF, what is the recommended first-choice medication, if no contraindication exists?

Antiplatelet medication

Defibrase

$105 \quad 5.5 \%$

Others, i.e., traditional Chinese medicine

Q6. What is the target INR for ischemic stroke or TIA patients with AF receiving anticoagulation with a vitamin $\mathrm{K}$ antagonist?

$$
1-2
$$

$2-3^{b}$

3-4

4-5

$\begin{array}{ll}180 & 9.4 \% \\ 1,507 & 78.9 \% \\ 195 & 10.2 \% \\ 28 & 1.5 \%\end{array}$

Q7. For ischemic stroke or TIA patients with AF who are unable to take oral anticoagulants, what medication is recommended?

Aspirin alone ${ }^{b}$

Clopidogrel alone

Combination of clopidogrel and aspirin

Do not use any other medications

Q8. For ischemic stroke or TIA with acute myocardial infarction complicated by left ventricular mural thrombus formation i dentified by echocardiography or other cardiac imaging techniques, for at least how long should the patients be treated with oral anticoagulation?

3 months 
Table 3 Numbers and proportions of community physicians' $(N=1,910)$ answers to multiple-choice questions on acute treatment and secondary prevention of ischemic stroke or TIA ${ }^{a}$ (Continued)

\begin{tabular}{|c|c|c|}
\hline \multicolumn{3}{|c|}{$\begin{array}{l}\text { Q9. For ischemic stroke or TIA patients with rheumatic mitral valve disease, is long-term warfarin therapy recommended whether } \\
\text { or not AF is present? }\end{array}$} \\
\hline Yes $^{\mathrm{b}}$ & 1,215 & $63.6 \%$ \\
\hline No & 487 & $25.5 \%$ \\
\hline No idea & 208 & $10.9 \%$ \\
\hline \multicolumn{3}{|c|}{$\begin{array}{l}\text { Q10. For patients with noncardioembolic ischemic stroke or TIA, what medications are recommended to reduce the risk of } \\
\text { recurrent stroke and other cardiovascular events? }\end{array}$} \\
\hline Antiplatelets ${ }^{\mathrm{b}}$ & 1,280 & $67.0 \%$ \\
\hline Oral anticoagulants & 29 & $26.1 \%$ \\
\hline Traditional Chinese medicine & 131 & $6.9 \%$ \\
\hline \multicolumn{3}{|c|}{ Q11. Is aspirin plus clopidogrel recommended for routine secondary prevention after ischemic stroke or TIA? } \\
\hline Yes & 886 & $46.4 \%$ \\
\hline $\mathrm{No}^{\mathrm{b}}$ & 774 & $40.5 \%$ \\
\hline No idea & 250 & $13.1 \%$ \\
\hline \multicolumn{3}{|c|}{ Q12. Is there evidence that reducing homocysteine levels prevents stroke recurrence in ischemic stroke or TIA patients? } \\
\hline Yes & 1,322 & $69.2 \%$ \\
\hline $\mathrm{No}^{\mathrm{b}}$ & 217 & $11.4 \%$ \\
\hline No idea & 371 & $19.4 \%$ \\
\hline \multicolumn{3}{|c|}{ Q13. Is postmenopausal hormone therapy recommended for women with ischemic stroke or TIA? } \\
\hline Yes & 562 & $29.4 \%$ \\
\hline $\mathrm{No}^{\mathrm{b}}$ & 894 & $46.8 \%$ \\
\hline No idea & 454 & $23.8 \%$ \\
\hline
\end{tabular}

$A F$ atrial fibrillation, INR international normalized ratio, $r$ PAA recombinant tissue-type plasminogen activator, TIA transient ischemic attack

${ }^{a}$ The questions and answers were designed to reflect relevant American Heart Association/American Stroke Association guidelines (AHA/ASA) [7, 10]

${ }^{\mathrm{b}}$ Recommendations from relevant AHA/ASA guidelines $[7,10]$

the use of anticoagulant medications. A national clinical trial with over 3000 ischemic stroke or TIA patients discharged from 47 hospitals in China, reported that at 1-year post stroke, $81.1 \%, 36.1 \%$ and $68.6 \%$ of the patients, respectively, adhered to the antiplatelet, anticoagulant, and antihypertensive medications prescribed at discharge.cs [20] Since community physicians often prescribe daily medications for patients who have had an ischemic stroke or TIA, more education and communication programs are needed to equip them with better knowledge in this area. Moreover, providing community physicians with ready-to-use tools such as portable reference cards outlining stroke scores and essential secondary prevention recommendations of current guidelines, may help to narrow the evidence-based practice gaps in community care centers.

The strengths of this study are that all the 11 prefectures of Shanxi Province were surveyed and that the response rate was high, mainly because the physicians, as government employees, viewed participation as mandatory. Use of a simplified questionnaire that did not cover all the essential secondary prevention measures for ischemic stroke or TIA patients (e.g., management of lipid profiles and diabetes) was a study limitation. In the near future, independently designed studies of this kind that are nationwide in scope, or incorporated into national stroke registry programs, would further describe the gaps between community physician practices and evidence-based guidelines. The results of those studies would help in the design, and initiation of relevant education and support programs in China.

\section{Conclusions}

This study revealed a huge gap among community physicians in the knowledge and clinical practice of the recommendations contained in the most recent Chinese and AHA/ASA guidelines for secondary prevention of ischemic stroke and TIA. There is a great need for education and training of the community physicians in this area.

\section{Competing interests}

The authors have no conflicts of interest to declare

\section{Authors' contributions}

Chen Chen, Jintao Wang designed the study, Chen Chen, Xiaoyuan Qiao, Huijie Kang, Lixia Bai participated survey questionnaire construction and data collection, Ling Ding performed statistics, Chen Chen, Jingtao Wang drafted the manuscript and JTW made the final revision of manuscript. 


\section{Acknowledgements}

The study was funded by grants from the Key Scientific and Technical Program (2011119), Health Department of Shanxi Province, and the Scientific and Technical Infrastructure and Facility Development Program (2012091003-0103), Shanxi Province, China.

\section{Author details}

${ }^{1}$ Department of Epidemiology, School of Public Health, Shanxi Medical University, Taiyuan, Shanxi Province, China. ${ }^{2}$ Department of Geriatrics, The Third People's Hospital of Shanxi Province, Taiyuan, Shanxi, China.

Received: 11 October 2014 Accepted: 28 October 2015

Published online: 03 November 2015

\section{References}

1. Feigin VL, Forouzanfar MH, Krishnamurthi R, Mensah GA, Connor M, Bennett DA, et al. Global and regional burden of stroke during 1990-2010: findings from the Global Burden of Disease Study 2010. Lancet. 2014;383(9913):245-54.

2. Hillen T, Coshall C, Tilling K, Rudd AG, McGovern R, Wolfe CD. Cause of stroke recurrence is multifactorial: patterns, risk factors, and outcomes of stroke recurrence in the South London Stroke Register. Stroke. 2003;34(6):1457-63.

3. Hankey GJ. Long-term outcome after ischaemic stroke/transient ischaemic attack. Cerebrovasc Dis. 2003;16 Suppl 1:14-9.

4. Wang $Y, X u$ J, Zhao X, Wang D, Wang C, Liu L, et al. Association of hypertension with stroke recurrence depends on ischemic stroke subtype. Stroke. 2013;44(5):1232-7.

5. Wu J, Jia LF, Jia JP. Awareness of secondary stroke prevention guidelines among neurologists in China: a cross-sectional online survey. Chin Med J (Engl). 2012;125(11):1867-70.

6. Furie KL, Kasner SE, Adams RJ, Albers GW, Bush RL, Fagan SC, et al. Guidelines for the prevention of stroke in patients with stroke or transient ischemic attack: a guideline for healthcare professionals from the american heart association/american stroke association. Stroke. 2011;42(1):227-76.

7. European Stroke Organisation Executive Committee; E. S. O. Writing Committee. Guidelines for management of ischaemic stroke and transient ischaemic attack 2008. Cerebrovasc Dis. 2008;25(5):457-507.

8. Chinese Medical Association. Chinese National Guidelines for Prevention of Ischemic Stroke and Transient Ischemic Attack. Chin J Neurol. 2010;43(2):1-8.

9. Chinese Medical Association. Chinese stroke rehabilitation management guideline. Chin J Rehabil Theory Pract. 2011;4:301-18.

10. Jauch EC, Saver JL, Adams HP, Bruno A, Connors JJ, Demaerschalk BM, et al. Council on Peripheral Vascular Disease; and Council on Clinical Cardiology, Guidelines for the early management of patients with acute ischemic stroke: a guideline for healthcare professionals from the American Heart Association/American Stroke Association. Stroke. 2013;44(3):870-947.

11. Brott T, Adams Jr HP, Olinger CP, Marler JR, Barsan WG, Biller J, et al. Measurements of acute cerebral infarction: a clinical examination scale. Stroke. 1989;20(7):864-70.

12. Sun TK, Chiu SC, Yeh SH, Chang KC. Assessing reliability and validity of the Chinese version of the stroke scale: scale development. Int J Nurs Stud. 2006;43(4):457-63.

13. Barber M, Fail M, Shields M, Stott DJ, Langhorne P. Validity and reliability of estimating the scandinavian stroke scale score from medical records. Cerebrovasc Dis. 2004;17(2-3):224-7.

14. Tsivgoulis G, Spengos K, Manta P, Karandreas N, Zambelis T, Zakopoulos N, et al. Validation of the ABCD score in identifying individuals at high early risk of stroke after a transient ischemic attack: a hospital-based case series study. Stroke. 2006;37(12):2892-7.

15. Adams Jr HP, del Zoppo G, Alberts MJ, Bhatt DL, Brass L, Furlan A, et al. Guidelines for the early management of adults with ischemic stroke: a guideline from the American Heart Association/American Stroke Association Stroke Council, Clinical Cardiology Council, Cardiovascular Radiology and Intervention Council, and the Atherosclerotic Peripheral Vascular Disease and Quality of Care Outcomes in Research Interdisciplinary Working Groups: the American Academy of Neurology affirms the value of this guideline as an educational tool for neurologists. Stroke. 2007;38(5):1655-711.

16. Bushnell CD, Olson DM, Zhao X, Pan W, Zimmer LO, Goldstein LB, et al. Secondary preventive medication persistence and adherence 1 year after stroke. Neurology. 2011;77(12):1182-90.
17. Fonarow GC, Reeves MJ, Smith EE, Saver JL, Zhao X, Olson DW, et al. Characteristics, performance measures, and in-hospital outcomes of the first one million stroke and transient ischemic attack admissions in get with the guidelines-stroke. Circ Cardiovasc Qual Outcomes. 2010;3(3):291-302.

18. Liu L, Wang D, Wong KS, Wang Y. Stroke and stroke care in China: huge burden, significant workload, and a national priority. Stroke. 2011;42(12):3651-4.

19. Wang Y, Cui L, Ji X, Dong Q, Zeng J, Wang Y, et al. The China National Stroke Registry for patients with acute cerebrovascular events: design, rationale, and baseline patient characteristics. Int J Stroke. 2011;6(4):355-61.

20. Peng B, Ni J, Anderson CS, Zhu Y, Wang Y, Pu C, et al. Implementation of a structured guideline-based program for the secondary prevention of ischemic stroke in China. Stroke. 2014;45(2):515-9.

\section{Submit your next manuscript to BioMed Central and take full advantage of:}

- Convenient online submission

- Thorough peer review

- No space constraints or color figure charges

- Immediate publication on acceptance

- Inclusion in PubMed, CAS, Scopus and Google Scholar

- Research which is freely available for redistribution 